\title{
Experimental and numerical analysis for potential heat reuse in liquid cooled data centres
}

Andreu Carbó $^{1}$, Eduard Oró ${ }^{1, *}$, Jaume Salom ${ }^{1}$, Mauro Canuto ${ }^{2}$, Mario Macías ${ }^{2}$, Jordi Guitart ${ }^{2}$

${ }^{1}$ Catalonia Institute for Energy Research, IREC. Jardins de les Dones de Negre 1, 08930, Sant Adrià de Besòs (Barcelona), Spain

${ }^{2}$ Barcelona Supercomputing Center and Universitat Politècnica de Catalunya, C/Jordi Girona 29, 08034 Barcelona, Spain

*Corresponding author email: eoro@irec.cat; tel: +34 933562615

\begin{abstract}
The rapid increase of data centre industry has stimulated the interest of both researchers and professionals in order to reduce energy consumption and carbon footprint of these unique infrastructures. The implementation of energy efficiency strategies and the use of renewables play an important role to reduce the overall data centre energy demand. Information Technology (IT) equipment produce vast amount of heat which must be removed and therefore waste heat recovery is a likely energy efficiency strategy to be studied in detail. To evaluate the potential of heat reuse a unique liquid cooled data centre test bench was designed and built. An extensive thermal characterization under different scenarios was performed. The effective liquid cooling capacity is affected by the inlet water temperature. The lower the inlet water temperature the higher the liquid cooling capacity; however, the outlet water temperature will be also low. Therefore, the requirements of the heat reuse application play an important role in the optimization of the cooling configuration. The experimental data was then used to validate a dynamic energy model developed in TRNSYS. This model is able to predict the behaviour of liquid cooling data centres and can be used to study the potential compatibility between large data centres with different heat reuse applications. The model also incorporates normalized power consumption profiles for heterogeneous workloads that have been derived from realistic IT loads.
\end{abstract}

Keywords: Data Centre; liquid cooling; IT load; experimentation, numerical modelling.

\section{Introduction}

During the last years the rapid increase of cloud computing, data storage and internet use have resulted in a dramatic growth in the number of data centres. These unique installations work 24 hours a day, 365 days a year, and the miniaturization of the components and increase of the processing power results in a huge energetic density. Nowadays, the energy demand per square meter of a data centre is approximately up to 100 times higher than a regular office [1]. As a consequence, the energy consumption and carbon footprint of this emergent industry started to become a considerable worldwide concern, being the $1.3 \%$ of the world electricity consumption in 2012 [2]. Most of the power consumed by the Information Technology (IT) equipment is converted in excess heat, which must be removed to avoid the damage of the equipment. The energy requirement of the cooling system represents up to $40 \%$ of the overall data centre energy consumption [3].

Traditionally the refrigeration in these unique facilities has been done by air cooling systems. Its initial low efficiency has been improved implementing different methods such as hot/cold aisles containment, variable fan speed, etc. [4], obtaining savings up to $70 \%$ [5]. However, Moore's 
law [6], which states that transistor density doubles every 2 years, continues to be true nowadays. This means that, due to the exponential increase in IT energy density, in few years the energy density of the IT equipment will reach values up to $50 \mathrm{~kW} /$ rack and therefore the solely use of air cooling system will be insufficient to evacuate all the heat generated by the servers [7]. To overcome this problem the data centre industry is already investigating and implementing the use of liquid cooling systems due to the higher heat removal capacity and the ability to cool specific system components to a greater degree [8]. Some applications use mineral oil [9], refrigerants [10], or water, which it is more common, cheaper and presents several possibilities for heat reuse [2].

Recently many researchers have been focusing on the evaluation of the potential heat reuse in data centres. Ebrahimi et al. [2] performed a literature survey about the possible waste heat reuse technologies, and concluded that their applicability depended drastically on the quality of the recovered heat. Table 1 collects the suitability of the waste heat technologies for data centres, for three different cooling strategies. Notice that the air cooling provides low quality heat, while with two-phase cooling (refrigerant instead of water) high temperature applications can be applied. Water cooling which obviously is less complex than the two-phase system provides intermediate quality heat.

Lately, various investigators have been focusing on analysing the potential implementation of the aforementioned technologies in data centres. Marchinicen et al. [10] reveal that a large data centre (32.5MW of IT power) could improve by $2.2 \%$ the thermal efficiency of a nearby $175 \mathrm{MW}$ coal power plant by reusing the $60^{\circ} \mathrm{C}$ waste cooling water in pre-heating the plant's feed water. Ebrahimi et al. [3] showed that the waste heat extracted from 3 to 5 servers can be used to cool an additional one, with a minimum recovery temperature of $65^{\circ} \mathrm{C}$ by using an absorption refrigeration technique. Nonetheless, those temperature values seem complicated to achieve when using water as the refrigerant. In that sense, in the water cooling system proposed by IBM and studied by Gao et al. [11], the temperature recovered after the server rack at full IT load was only $43^{\circ} \mathrm{C}$. There are already some data centres that reuse heat for other applications. The Uspenski data centre located in Helsinki (Finland) uses the warm water from its facility to heat up 500 houses in the neighbourhood [12]. Another example of heat reuse comes from the IBM data centre in Uitikon (Switzerland), which sends its waste heat to warm a public swimming pool located nearby [13]. Here, the hot air generated by the data centre flows through heat exchangers to warm water that is then pumped into the nearby pool. Moreover, IBM proposed a facility that would allow reducing the cooling energy up to $95 \%$ utilizing a combination of warm water cooling of the electronics and liquid-side economization with a dry air heat exchanger [11].

However, most of the waste heat reuses technologies for data centres are still in the design or validation phase. An important issue is that the industry requires robust mathematical models able to provide accurate values of operation or to correctly extrapolate experimental results from a small test bench to a large facility. Generally the servers and the cooling system are modelled with the heat transfer equation, considering convection and conduction mechanisms. Breen et al. [7] performed a thermal equilibrium model of an air cooled rack to obtain flow rate, pressure drop and heat transfer coefficients that were used to characterize the system. Douchet et al. [8] described the rack with a nodal model, assigning the nodes to the IT components, and validating the calculations later with thermocouples attached to those components. Another approach was 
resistance of the system in function of the measured temperatures. Moreover, Zhang et al. [14] not only performed an energy balance but created a TRNSYS model to simulate the heat recovery system and compare it with other heating supplies as Ground Source Heat Pump (GSHP) or Seasonal Thermal Energy Storage (STES). The study concluded that heat recovered from data centres provides a more stable source of heat than GSHP and at a lower cost than STES.

This study aims first to characterize the potential heat reuse of a liquid cooled data centre under different boundary conditions such as water temperature and mass flow rate and second to develop and to validate with experimental data a dynamic energy model able to predict the operational behaviour of liquid refrigerated data centre. To do so, a unique micro data centre test bench with an IT power capacity of $1.2 \mathrm{~kW}$ has been designed and built in the Catalonia Institute for Energy Research (IREC) facilities [15]. Moreover, the relationship between server usage and server consumption was developed for different common IT loads (HPC, data and web).

\section{Nomenclature}

\begin{tabular}{cl}
\hline & \multicolumn{1}{c}{ Roman letters } \\
\hline A & Area $\left[\mathrm{m}^{2}\right]$ \\
$\mathrm{C}$ & Specific heat $[\mathrm{kJ} / \mathrm{kg} \mathrm{K}]$ \\
$\varepsilon$ & effectiveness \\
$\mathrm{E}$ & Electrical power $[\mathrm{W}]$ \\
$\mathrm{h}$ & Heat transfer coefficient $\left[\mathrm{W} / \mathrm{m}^{2} \cdot \mathrm{K}\right]$ \\
$\dot{\mathrm{m}}$ & Mass flow $(\mathrm{kg} / \mathrm{s})$ \\
$\mathrm{P}$ & Pressure $[\mathrm{bar}]$ \\
$\dot{Q}$ & Power $(\mathrm{W})$ \\
$\mathrm{T}$ & Temperature $\left[{ }^{\circ} \mathrm{C}\right]$ \\
$\mathrm{U}$ & Thermal transmittance $\left[\mathrm{W} / \mathrm{m}^{2} \cdot \mathrm{K}\right]$ \\
$\mathrm{V}$ & Volume \\
\hline & $\quad$ Acronyms \\
\hline ASHRAE & American Society of Heating, Refrigerating and Air Conditioning \\
& Engineers \\
$\mathrm{CPU}$ & Central Processing Unit \\
GSHP & Ground Source Heat Pump \\
IT & Information Technology \\
HVAC & Heating, Ventilation, and Air Conditioning \\
HPC & High Performance Computing \\
IREC & Catalonia Institute for Energy Research \\
RH & Relative Humidity \\
PSU & Power Distribution Unit \\
SEILAB & Semi-Virtual Energy Integration Laboratory \\
TRNSYS & Transient System Simulation Tool \\
STES & Seasonal Thermal Energy Storage \\
\hline & \\
\hline air & Air \\
in & Inlet \\
MB & Motherboard \\
out & Outlet \\
rack & Rack \\
&
\end{tabular}




\begin{tabular}{cl} 
rack-air & Rack to air \\
s1 & Shelf 1 \\
s2 & Shelf 2 \\
server & server \\
sup & Superficial \\
t & Total \\
w & Water \\
ws & Whitespace \\
\hline
\end{tabular}

113

\section{Methodology}

\subsection{Micro data centre characteristics}

In order to characterize the potential heat reuse of liquid cooled data centres, a micro data centre test bench has been designed and built in the Semi-Virtual Energy Integration Laboratory (SEILAB) in IREC [15]. The data centre is composed of two independent shelves which are placed inside a commercial rack. Each of the shelves contains 2 liquid-cooled servers. These servers have 2 processors Intel Xeon with 8 cores each and are provided by Megware [16].

In order to control the boundary conditions of the rack (ambient temperature and relative humidity), it is placed inside the climate chamber of the laboratory. These servers are liquid cooled and therefore they have a pipe network which provides cooling directly to the Central Processing Unit (CPU) and to the memory by fins (Figure 1). Additionally, in order to fulfil the manufacturer specifications supplementary air cooling must be also provided. This additional cooling system should provide around $25 \%$ of the total refrigeration capacity. Therefore, the micro test bench includes an extra fan able to blow refrigerated air into the servers. Additionally, the servers have already installed internal fans in the power distribution unit (PSU) that circulate the air through its interior.

\subsection{Cooling operational management}

According to the water cooling piping configuration, the system can be defined to be in parallel or in series configuration.

\section{Parallel set-up}

In parallel configuration the cold water splits equally in both shelves, and therefore same inlet conditions (water temperature and flow rate) are expected in each shelf. In this configuration, the total water flow rate to the rack is therefore twice the flow rate of a single shelf. Notice that if the IT load is similar among the servers, the outlet water conditions should be equal.

\section{Series set-up}

In series configuration the water outlet of one shelf is the inlet of the other. During the experimentation, the cold water enters the upper shelf, getting warmed in the process and then cools the bottom shelf. In this configuration the water flow rate is the same for each shelf. Implementing this cooling configuration, higher water recovery temperatures are expected, but there must be taken in account that at any case, the maximum water inlet temperature should be lower than $40^{\circ} \mathrm{C}$ as specified by the manufacturer.

\subsection{Experimental measurements}

Different air and water temperature sensors, air humidity sensors, pressure sensors, flow rates 
sensors and energy consumption sensors were installed to characterize the micro data centre test bench (Figure 2). The water and air temperatures were measured using Pt-100 sensors with an accuracy of $+/-0.25 \mathrm{~K}$. The air humidity sensors have an accuracy of $+/-3 \%$ for relative humidity between $0 \%$ and $90 \%$ and $+/-5 \%$ for relative humidity between $90 \%$ and $100 \%$. The water flow rate was measured using vortex flow sensors which were calibrated with an accuracy of $+/-1 \%$ and the water pressure was measured with pressure transmitter with an accuracy of $+/-1 \%$. Finally the power consumption of the servers was measured using the electric power system SENTRON PAC3100 from Siemens with a power accuracy of $+/-1 \%$. Moreover, the lm-sensors tool [17] was used to monitor CPUs temperatures. This utility collects information about the temperature of each physical CPU core and each socket. The motherboard temperature was also measured using ipmitool [18]. Table 2 shows all the variables measured and monitored continuously during the experimentation.

\subsection{Experiments definition}

Following indications from the manufacturer (Table 3), the experiments for the potential heat reuse characterization were done varying the inlet water temperature from 20 to $40{ }^{\circ} \mathrm{C}$ in steps of $4{ }^{\circ} \mathrm{C}$; and the water flow rate from 0.5 to $1.5 \mathrm{l} / \mathrm{min}$ in steps of $0.5 \mathrm{l} / \mathrm{min}$. Following ASHRAE recommendations [19], the air inlet conditions can also vary from 18 to $27^{\circ} \mathrm{C}$ and from 20 to 80 $\%$ Relative Humidity (HR). But usually, the inlet air conditions do not vary that much, being a standard operational range of $20-24{ }^{\circ} \mathrm{C}$ and $50 \%$ RH. Preliminary experimentation showed that the air inlet condition variation (mainly temperature variation) had no considerable effect in the CPU temperatures and therefore the IT load. Figure 3 shows the temperatures of the system (water and air inlet and outlet temperatures and CPU and motherboard temperatures) and the data centre consumption. On one hand, during the experimentation, inlet air temperature was varied and CPU temperature nor server consumption due to temperature was not affected. On the other hand, the motherboard temperature was slightly influenced by the inlet air temperature. Notice that the normal operational temperature range for a motherboard is between 60 and $70{ }^{\circ} \mathrm{C}$, being the maximum allowable temperature up to $95^{\circ} \mathrm{C}$ [20]. Thus the variation on the air inlet temperature affected the motherboard temperature variation but it was always within operational temperature range. Consequently, due to the fact first that standard data centres operates with constant air inlet conditions and second the air inlet temperature variation does not affect the CPU temperature and thus the server consumption, the air inlet conditions were kept constant at $22.5^{\circ} \mathrm{C}$ and $50 \% \mathrm{RH}$ during the experimentation.

The servers already have a small fan but in order to ensure correct air cooling an additional fan was installed to extract air from the rack. In real infrastructures, it can be difficult to well-size this additional air cooling system without previous experimentation. For this reason, the effect of the exhaust fan on the server performance has been studied in detail. Figure 4 shows water and IT components temperatures before and after the additional fan was switched off (min 80). As seen in the figure, the motherboard temperature increased $4{ }^{\circ} \mathrm{C}$ while the CPUs temperatures were not affected. Thus, since the motherboard temperature during the experimentation stayed between the normal temperature ranges $\left(60-70{ }^{\circ} \mathrm{C}\right)$, the additional air cooling system can be avoided or at least reduced. Nevertheless, in the experimentation for the heat reuse characterization this additional air cooling system was used for security issues.

In order to study the higher potential for heat reuse, the IT load was set at its maximum, which supposes approximately an IT power consumption of $1070 \mathrm{~W}$. In order to run the maximum IT 
load, a web framework based on the stress tool [21] that allows to automate the execution of the benchmark by changing its parameters. By spawning different number of threads it is possible to impose a configurable amount of CPU, memory, $\mathrm{I} / \mathrm{O}$, and disk stress on the system. Thus, the configuration which implied the maximum IT power consumption was found out and used during the experimentation.

\section{System modelling}

The software TRNSYS [22], a flexible graphically based software environment used to simulate the behaviour of transient systems is used to model the system [23]. The whitespace is modelled with a single lumped capacitance single-zone building with internal gains (Type 759). This means that the structure is subjected to internal gains (IT and miscellaneous gains) and to building losses. The racks were modelled as lumped mass (Type 963) which means that they can be characterized by the rack temperature and the heat transfer to its surrounding environment which is the whitespace. Here capacitance effects i.e. rack structure and servers are included. The use of this type allows implementing direct cooling technology by means of negative internal gains. Those components were connected according to the system configuration already described and shown in Figure 5.

The main parameters to characterize the lumped capacitance model are the volume of the white space $(V)$, the thermal capacitance of the white space $\left(C_{w s}\right)$ which include the capacitances of the building materials, furnishings and conditioned air, and the overall heat transfer coefficient (UA) of the whitespace to the surrounding ambient. This coefficient is used to calculate the skin losses/gains from the IT room to the exterior. It is defined based on the $U$-value of the data centre walls and the area $\left(A_{w s}\right)$ in contact with the external environment. Moreover, the main parameters to characterize the IT racks through the lumped mass model are the thermal capacitance of the IT equipment $\left(C_{\text {rack }}\right)$, the heat transfer area of the equipment to the air $\left(A_{\text {rack }}\right)$ and the heat transfer coefficient from the racks to the air in the IT room $\left(h_{\text {rack-air }}\right)$.

For each time step in the simulation process, the thermal performance of the whitespace model will respond to boundary conditions. Heat gains due to the IT equipment $\left(\dot{Q}_{I T}\right)$ together with the effects of direct liquid cooling system $\left(\dot{Q}_{w}\right)$, as negative internal gains, are implemented in the IT racks component. Therefore, it is possible to calculate average temperature of the racks $\left(T_{\text {rack }}\right)$, air and water inlet and outlet temperatures to and from the IT equipment. Sensible cooling power of the air $\left(\dot{Q}_{a i r}\right)-$ Eq. 1 - and liquid cooling power $\left(\dot{Q}_{w}\right)-$ Eq. 2 - can be calculated using the following equations. Moreover, the effectiveness of the heat transfer can be calculated using Eq. 3.

$$
\begin{array}{ll}
\dot{Q}_{\text {air }}=\dot{m}_{\text {air }} \cdot C_{\text {air }} \cdot\left(T_{\text {air.out }}-T_{\text {air.In }}\right) & \text { Eq. } 1 \\
\dot{Q}_{w}=\dot{m}_{w} \cdot C_{w} \cdot\left(T_{w . \text { out }}-T_{\text {w.In }}\right) & \text { Eq. } 2 \\
\dot{Q}_{w}=\varepsilon \cdot \dot{Q}_{\text {air }} & \text { Eq. } 3
\end{array}
$$




\subsection{Potential heat reuse characterization}

\section{Parallel configuration results}

236 This section presents the potential heat reuse characterization results for the parallel case. The 237 results show linear relation between the parameters analysed: the higher the water inlet 238 temperature, the higher the outlet water temperature; the lower the inlet water temperature the

\section{higher the cooling capacity.}

Figure 6.a shows the relation between inlet water temperature and outlet water temperature for different water flow rates. Notice that the maximum water outlet temperature is $50^{\circ} \mathrm{C}$ when the inlet water temperature is $40^{\circ} \mathrm{C}$ at the minimum flow rate $(0.5 \mathrm{l} / \mathrm{min})$. Moreover this figure also shows the temperature difference between them $\left(T_{\text {diff }}\right)$ which is also dependent on the inlet water temperature has highly dependence on the flow rate. Figure 6.b shows the relationship between inlet water temperature and the water cooling capacity (both in absolute value $-\mathrm{W}-$ and in percentage of the IT consumption). Here it is presented that configurations with lower inlet water temperatures provide higher cooling capacity. Water inlet temperature around $20^{\circ} \mathrm{C}$ provides $10 \%$ more cooling capacity than with water inlet temperatures at $40^{\circ} \mathrm{C}$. As expected, higher water flow rates provide more cooling capacity. Notice that at high flow rates the cooling capacity can reach values up to $87 \%$. These results clearly show that a balance between high outlet temperatures and high liquid cooling capacities should be done before planning the final cooling layout.

Figure 7 shows the dependency between the inlet water temperature and the IT power consumption and average CPU temperatures. The average CPU temperature was calculated doing the average of all the physical CPU temperatures of the servers. As expected, the higher the inlet water temperature the higher the CPU temperature while higher water flow rates allowed working at lower CPU temperatures. In the experimentation performed, the maximum CPU temperatures measured where up to $60^{\circ} \mathrm{C}$ which are quite lower than the allowable temperature by the manufacturer (up to $82^{\circ} \mathrm{C}$ ) [20]. This graph also shows the IT consumption under the same IT load. Notice that the consumption increases up to $3 \%$ from the coolest to the warmest water inlet temperature. This phenomenon can be attributed to the leakage currents inside the silicon chips at higher temperatures, mixed with higher internal fan power consumption [24].

\section{Series configuration results}

The trends observed in the previous configuration are also observed in the series cooling configuration (Figure 8). Notice that in this configuration, the water temperature difference between inlet and outlet is twice as before since the water is going through the piping the double of time (Figure 8.a). This phenomenon indicates that with lower water inlet temperatures the data centre provides warmer outlet water. Figure 8.b presents the water cooling power capacity for different water flow rates in function of the inlet water temperature. Similarly with the previous configuration, the lower the flow rate the lower the cooling capacity. The results also show that in terms of water cooling capacity there is slightly difference between operating with $1 \mathrm{l} / \mathrm{min}$ or with $1.5 \mathrm{l} / \mathrm{min}$. Therefore, this phenomenon demonstrates that the water flow rate can be limited up to $1 \mathrm{l} / \mathrm{min}$ in the current servers since there is no expected benefit in terms of cooling power capacities and outlet water temperatures (less than $3^{\circ} \mathrm{C}$ ). This limit reduction will 
impact on the operational cost reducing the water pump consumption.

\section{Summary}

In function of the application connected to the data centre in order to reuse the waste heat, different cooling strategies and configurations are possible. Table 4 summarizes some results for different scenarios:

- Warmer water obtained: the maximum outlet water temperature reached in both configurations is around $50{ }^{\circ} \mathrm{C}$, however the series configuration allows increasing the water temperature much more, and therefore the inlet water temperature can be much lower $\left(29^{\circ} \mathrm{C}\right)$.

- Larger water temperature increase: the preferable configuration is the series layout, reaching values up to $22.5^{\circ} \mathrm{C}$.

- Higher heat extracted by the water cooling: if the liquid cooling capacity is high enough, the additional air cooling system can be avoided. Here, both configurations can reach values above $85 \%$. However the series configuration needs half of the total water flow rate and is able to provide higher water outlet temperatures, therefore it is preferable. Notice as well that in this situation the best configuration is when the minimum inlet water temperature and the maximum water flow rate is used.

- Minimum IT consumption: To experience the minimum IT consumption for doing the same IT load, minimum inlet water temperature and maximum water flow rate is required. In this situation, the CPU temperatures are low and thus the IT consumption is not influenced by current leakage phenomena.

In order to choose the most adequate cooling configuration, the cost of doubling the flow rate in the parallel configuration, and the extra inlet pressure needed in the series configuration should be calculated in detail. In general increasing the pressure head leads to using more powerful and therefore more expensive pumps. However, if the pump is dimensioned for a series use, changing later to the parallel configuration would suppose operating farther away from the design conditions and therefore less efficiently.

In the results presented it is easy to appreciate that some of the variables depend linearly with $T_{w . i n}$, and at the same time the trends are repeated for parallel and series configurations. If the attention is focused in one single server, the results are consistent all over the experiments, for example the outlet temperature can be modelled with a linear relation, as:

$$
T_{\text {w.out }}=A \cdot T_{\text {w.in }}+B \quad \text { Eq. } 4
$$

where $A$ and $B$ are parameters that depend on the water flow rate of the shelf $\dot{m}_{w}$. As it can be observed in Figure 9, this correlation fits perfectly the values observed in the experiments, and could be used for every case in those shelves, both in parallel and series cases, always that the IT load is fixed at maximum.

Similarly, the water cooling percentage is also linear with the water inlet temperature. Moreover, the difference between using a flow rate of 1 or $1.5 \mathrm{l} / \mathrm{min}$ is really small, especially for higher inlet temperatures, as it can be seen in Figure 10.

\subsection{Model validation}

Two different validation processes are evaluated in order to guarantee the robustness of the 
model. The first is to validate the thermo-physical characteristics of the system and the second is to validate dynamically the model proposed. Table 5 presents the values of the thermo-physical

For the first validation, air and water temperature inlets are fixed. The experimentation starts with the servers switched off and once the system is in steady state the servers are switched on to the idle condition (approx. $420 \mathrm{~W}$ ). Figure 11.a shows a good agreement between the numerical results and experimental water outlet temperatures as well as the water cooling capacity. Notice that during the transient phase the model predicts the outlet temperature without any error and when the steady state is reached the temperature difference between the modelled temperature and the real one is less than $0.4^{\circ} \mathrm{C}$. Additionally, Figure 11.b presents the air outlet temperature; in this case the numerical values show a faster response time and the difference at steady state is larger, around $1^{\circ} \mathrm{C}$. This is understandable because this value depends highly on the sensor position in the set-up, which cannot be controlled in the model, which gives an average value.

For the second part of the validation process, dynamic experiments have been used. Figure 12 presents the experimental and numerical values during a parallel experiment, where inlet temperature is gradually changed. Here, not only the water temperature and liquid cooling capacity fits quite reasonable but the IT consumption which increases as the inlet water temperature increases. Therefore, both validation processes proves the consistency and robustness of the dynamic model developed.

\subsection{Extrapolation results to real data centres}

Once the model has been validated with experimental data it can be used to predict the potential heat reuse of real liquid cooled data centres. To simulate the power consumption of a data centre, the power requirements of servers are needed. They depend on the current computing load and therefore the usage patterns of the equipment that describe the IT load processed are needed. In real data centres, disparities in performance and power characteristics across servers and different scheduling, task migration or load balancing mechanisms, have effects on the cooling systems that are difficult to predict. For simplicity, three different homogeneous IT load (Web, HPC and Data) have been studied in the present manuscript:

- Web workload has real-time requirements: the users of such workload need to get a response to their petitions in few seconds (i.e. Google search, Facebook surf, etc.). There is not a typical resource consumption profile for web workloads but they may use CPU, memory, network or disk in several proportions. This workload has the particularity to follow a daily/weekly pattern.

- HPC workload is typically CPU intensive. They perform a large amount of floatingpoint operations for scientific calculations. Because HPC workloads may last for hours, or even days, they do not have real-time requirements, and they are usually allocated in job queues that may execute them hours or days after they are submitted by the users.

- Data workload is usually both memory and disk-intensive, while they can also use a high rate of CPU operations for data analysis. Despite of data workloads may have realtime requirements (i.e. a search query in Google), the authors consider data workloads without real-time requirements (i.e. background data analytics for business intelligence applications). 
372 Notice that HPC and Data workloads do not follow a given pattern, and they will depend on the access policy and dimension of the data centres of each institution. In the present study Web workload is a real pattern collected from the access log of an ISP within the UPC [25], while HPC and data workloads patterns are extracted from the CEA-Curie data centre which are publicly available in the Parallel Workloads Archive [26]. Figure 13 presents the three IT load whole year of study.

However, in order to predict the data centre consumption from the IT load, a relationship between server usage (IT load) and server consumption is developed. In the present study the definition of IT load is an additive function that considers the load rates of CPU, Main Memory, Disk and Network, pondered according to the measured impact of each term in late 2012 servers [27]. Firstly, different types of micro-benchmark for fully stressing the system were executed in order the reach the maximum real power of the system. These benchmarks included Ibench suite [28], Stress-ng [29], Sysbench [30], Prime95 [31], Pmbw [32], Fio [33] and Iperf3 [34]. After this initial process different benchmarks based on real-world software stacks from CloudSuite [35] for web and data benchmarks, and NAS Parallel Benchmarks [36] for HPC were also executed. With this experimentation the relation between IT load and power consumption can be draw. Notice that for its further adaptation to other hardware these correlations were normalized. Figure 14 shows the results of the experimentation and the regressions to predict different consumptions in function of the IT load. The variability in the power/load measurements show that there is not a generic power profile for software, because all the components of a host (CPU, memory, disk, network) do not work independently. They must coordinate because there are dependencies between data and procedures (and the usage of resources is variable across the same execution, depending of the availability of their required inputs at a given time).

In the current study four different IT load scenarios are under study: Scenario a) Data centre dedicated totally to HPC workload. Scenario b) Data centre dedicated totally to data workload. Scenario c) Data centre dedicated totally to web workload. Scenario d) Mixed used data centre; in this scenario IT load is compound by $40 \%$ web, $30 \%$ HPC and $30 \%$ data workload. Figure 15 presents the servers consumption in percentage of the total installed IT capacity for the four scenarios analysed. Notice that even though the HPC and data IT load have similar usage profiles, the expected power consumption for HPC data centres is higher because HPC workloads usually stress more the CPU, which has a higher weight in the overall power consumption, while data workloads perform intensive use of memory and disk, which forces CPU to be idle while it waits for the data.

For the study, a liquid cooling data centre with the servers already tested in the experimental part is considered. Each rack contains 42 shelves and each shelf has 2 servers with a maximum power consumption of $246 \mathrm{~W}$. Therefore, each rack can reach up to $20.6 \mathrm{~kW}$. Regarding the cooling configuration, a parallel cooling situation is analysed. Table 6 shows the boundary conditions of the cooling system.

Figure 17 and Figure 18 show the water temperature obtained from the rack outlet (a) and the heat extracted by liquid in each rack (b) for a flow rate of $0.51 / \mathrm{min}$ and $1 \mathrm{1} / \mathrm{min}$, respectively. As expected, the lower flow rate allows recovering water with the double temperature gain, while the higher flow rate provides between a $10 \%$ and a $15 \%$ more cooling. However, in this case 
the heat recovered is of very low quality, clearly not enough for the applications studied in 420 literature. Table 7 shows the average IT consumption and the water cooling capacity for the 421 different scenarios analysed.

422

423

424

425

426

427

428

429

430

431

432

433

434

435

436

437

438

439

440

441

442

443

444

445

446

447

448

449

450

451

452

453

454

455

456

457

458

459

460

461

462

463

464

\section{Conclusions}

Cooling demand in data centres represents a large amount of the overall energy consumption. The use of liquid cooling technology allows the infrastructure first to reduce its energy consumption due to the possibility to cool down the liquid by free cooling, and second to use the waste heat of the IT equipment in other applications such as space and network heating, greenhouse applications, etc. This manuscript presents the results of the potential heat reuse characterization of liquid cooled data centres. To do so, a unique micro data centre test bench with an IT power capacity of $1.2 \mathrm{~kW}$ was designed and build in IREC facilities.

The experimental results showed that the maximum outlet water temperature reached in the experimentation is around $50^{\circ} \mathrm{C}$; however the liquid cooling capacity in that situation is low. Notice that the liquid cooling capacity can reach values above $85 \%$ but the inlet water temperature must be low. The facility allows the connection of both servers in parallel or in series. When the servers are connected in series the water temperature increase through the system is higher (up to $22.5^{\circ} \mathrm{C}$ ) than in parallel configuration. It was observed an increase of the IT power consumption of $3 \%$ when the inlet water temperature was increased from 20 to $40{ }^{\circ} \mathrm{C}$, affecting the CPU temperature and thus trigger current leakage in the CPU. Therefore it's not possible to determine the best cooling configuration and balance between high water temperatures or high liquid cooling capacity is required for each specific waste heat reuse application. The effect of the air inlet conditions and the additional cooling system were also studied. The air inlet temperature increase does not affect the CPU temperature neither the IT power consumption. Similar results were found out when the additional air cooling system was switched off and therefore it can be avoided. The results also showed that the manufacturer's water flow rate recommendation can be decreased reducing the water pump energy consumption.

The benefit of developing a numerical model not only will help to well configure the cooling system but will allow extrapolating results to larger facilities. Therefore, a dynamic energy model was developed using TRNSYS software. The consistency and the goodness of the model are demonstrated by the validation of the numerical results with the experimental data. To have a more realistic simulation tool, the usage patterns that describe the IT load processed in the data centre are needed. Therefore, the relationship between server usage and server consumption was developed for different common IT loads (HPC, data and web). In order to show the potential use of the model, a rack with 42 shelves ( 84 liquid cooled servers) with a maximum IT power of $20.6 \mathrm{~kW}$ was modelled. It is important to highlight that this simulation was done only to show the potential use of the model but not to predict any particular data centre. As expected, the results show good agreement with the trends found in the experiments and the TRNSYS tool showed great potential and versatility for future studies.

The authors want to highlight that further research will focus on analysing data centres with higher inlet water temperatures and see the effect in both server behaviour and waste heat reuse. Moreover, it is also interesting to study the potential integration of liquid data centre with different applications such as district heating, building heating, greenhouse, fish farm, 
swimming pool, etc. and analyse in detail the technical and economic viability using the proposed dynamic model.

\section{Acknowledgments}

469 The research leading to these results has received funding from the European Union's Seventh Framework Programme FP7/2007-2013 under Grant Agreement nº 608679 - RenewIT.

\section{References}

[1] Oró E, Depoorter V, Garcia A, Salom J. Energy efficiency and renewable energy integration in data centres. Renew Sust Energ Rev 2015;42:429-445.

[2] Ebrahimi K, Jones GF, Fleischer AS. A review of data center cooling technology, operating conditions and the corresponding low-grade waste heat recovery opportunities. Renew Sust. Energ Rev 2014;31:622-638.

[3] Ebrahimi K, Jones GF, Fleischer AS. Thermo-economic analysis of steady state waste heat recovery in data centers using absorption refrigeration. Appl Energ 2015;139:384-397.

[4] Ham SW, Kima MH, Choi BN, Jeong JW. Simplified server model to simulate data center cooling energy consumption. Energ Buildings 2015;86:328-339.

[5] Ham SW, Park JS, Jeong JW. Optimum supply air temperature ranges of various air-side economizers in a modular data center. Appl Therm Eng 2015;77:163-179.

[6] Moore GE. Cramming More Components onto Integrated Circuits. Electronics 1965;1:114117.

[7] Breen TJ, Walsh EJ, Punch J, Shah AJ, Bash CE. From chip to cooling tower data center modeling: Part I Influence of server inlet temperature and temperature rise across cabinet. IEEE 2010. DOI: 10.1109/ITHERM.2010.5501421.

[8] Douchet F, Nortershauser D, Le Masson S, Glouannec P. Experimental and numerical study of water-cooled datacom equipment. Appl Therm Eng 2015;84:350-359.

[9] Haywood AM, Sherbeck J, Phelan P, Varsamopoulos G, Gupta SK. The relationship among CPU utilization, temperature, and thermal power for waste heat utilization. Energ Convers Manage 2015; 95:297-303.

[10] Marcinichen JB, Olivier JA, Thome JR. On-chip two-phase cooling of datacenters: Cooling system and energy recovery evaluation. Appl Therm Eng 2012;41:36-51.

[11] Gao T, David M, Geer J, Schmidt R, Sammakia B. Experimental and numerical dynamic investigation of an energy efficient liquid cooled chiller-less data center test facility. Energ Buildings 2015;9:83-96.

[12] Williams J. Make Wealth History. [Online]. Available: http://makewealthhistory.org/2014/05/16/building-of-the-week-the-uspenski-data-center/. [Accessed October 2015].

[13] Miller R. Data Center Used to Heat Swimming Pool. [Online]. Available: http://www.datacenterknowledge.com/archives/2008/04/02/-data-center-used-to-heatswimming-pool/. [Accessed October 2015].

[14] Zhang P, Wang B, Wu W, Shi W, Li X. Heat recovery from Internet data centers for space heating based on an integrated air conditioner with thermosyphon. Renew Energ 2015;80:396-406.

[15] Fuentes E, Schaefer D, Salom J. On the impact of realistic domestic hot water demand profiles on thermal storage stratification and energy efficiency. In Eurotherm Seminar 99: Advances in Thermal Energy Storage, Lleida, 2015. 
[16] MEGWARE Computer Vertrieb und Service GmbH [Online]. Available: http://www.megware.com/en/. [Accessed October 2015].

[17] Lm-sensors, 2015. [Online]. Available: http://www.lm-sensors.org/. [Accessed October 2015].

[18] Ipmitool, 2015. [Online]. Available: http://linux.die.net/man/1/ipmitool. [Accessed October 2015].

[19] ASHRAE, "Thermal Guidelines for Data Processing Environments, Third Edition," in ASHRAE TC 9.9, Atlanta, 2012.

[20] Intel Corporation, "Intel ${ }^{\circledR}$ Xeon ${ }^{\circledR}$ Processor E5-1600/E5-2600/E5-4600 v2 Product Families. External Design Specification (EDS) - Volume One," Intel Confidential, 2014.

[21] P systems. [Online]. Available: http://people.seas.harvard.edu/ apw/stress/. [Accessed October 2015].

[22] “TRNSYS software," [Online]. Available: http://www.trnsys.com/.

[23] Salom J, Oró E, Garcia A. Dynamic modelling of data centre whitespaces. Validation with collected measurements. Catalonia Institute for Energy Research, IREC, 2015.

[24] Moss D, Bean JH. Energy Impact of Increased Server Inlet Temperature, White Paper \#138. American Power Company by Schneider Electric, 2009.

[25] Macías M, Guitart J. SLA negotiation and enforcement policies for revenue maximization and client classification in cloud providers. Future Gener Comp Sy 2014;41:19-31.

[26] [Online]. Available: http://www.cs.huji.ac.il/labs/parallel/workload/.

[27] [Online].

Available: http://www.morganclaypool.com/doi/pdfplus/10.2200/S00516ED2V01Y201306CAC024.

[28] Delimitrou C Kozyrakis C. iBench: Quantifying interference for datacenter applications. In 2013 IEEE International Symposium on Workload Characterization (IISWC), 2013.

[29] [Online]. Available: http://kernel.ubuntu.com/ cking/stress-ng/. [Accessed October 2015].

[30] [Online]. Available: https://launchpad.net/sysbench. [Accessed October 2015].

[31] [Online]. Available: http://www.mersenne.org/download/. [Accessed October 2015].

[32] Pmbw - Parallel Memory Bandwidth benchmark / measurement. [Online]. Available: http://panthema.net/2013/pmbw/.

[33] Fio - Flexible I/O tester. [Online]. Available: http://git.kernel.dk/?p=fio.git;a=summary. [Accessed October 2015].

[34] Iperf3: A TCP, UDP, and SCTP network bandwidth measurement tool. [Online]. Available: https://github.com/esnet/iperf. [Accessed October 2015].

[35] [Online]. Available: http://parsa.epfl.ch/cloudsuite/cloudsuite.html. [Accessed October 2015].

[36] [Online]. Available: http://www.nas.nasa.gov/publications/npb.html. [Accessed October 2015]. 


\section{Table captions}

Table 1. Suitability of each waste heat technology for data centre applications [2].

Table 2. List of parameters measured in the data centre.

Table 3. Limits of the operational conditions provided by the manufacturer.

Table 4. Summary of the best-case scenarios found in the experiments.

Table 5. Thermo-physical characteristics of the elements of the system, as assumed at the model [25] [26].

Table 6. Boundary conditions of the cooling system for the case study.

Table 7. Average IT consumption and the water cooling capacity for the different scenarios analysed. 


\section{Table 1}

\begin{tabular}{|c|c|c|c|}
\hline Technology & $\begin{array}{l}\text { Air cooled data centre } \\
\left.\text { (waste heat } 45^{\circ} \mathrm{C}\right)\end{array}$ & $\begin{array}{c}\text { Water cooled data centre } \\
\left(\text { waste heat } 60^{\circ} \mathrm{C}\right)\end{array}$ & $\begin{array}{c}\text { Two phase data centre } \\
\text { (waste heat } 75^{\circ} \mathrm{C} \text { ) }\end{array}$ \\
\hline $\begin{array}{l}\text { HVAC/domestic hot } \\
\text { water }\end{array}$ & Yes & Yes & Yes \\
\hline District heating & Yes, with booster & Yes & Yes \\
\hline $\begin{array}{l}\text { Boiler feed water pre- } \\
\text { heating }\end{array}$ & No & Yes & Yes \\
\hline Absorption refrigeration & No & Yes & Yes \\
\hline Organic Rankine cycle & Yes, with booster & Yes & Yes \\
\hline Piezoelectrics & Yes & No & No \\
\hline Thermoelectrics & No & No & Yes \\
\hline Desalination & No & Yes & Yes \\
\hline Biomass processing & Yes & Yes & Yes \\
\hline
\end{tabular}


Table 2

\begin{tabular}{lll}
\hline Parameters & Definition & Units \\
\hline
\end{tabular}

Air refrigeration

\begin{tabular}{|c|c|c|}
\hline$T_{a i r, \text { in }}$ & Air inlet temperature & ${ }^{\circ} \mathrm{C}$ \\
\hline$T_{\text {air,out }}$ & Air outlet temperature & ${ }^{\circ} \mathrm{C}$ \\
\hline$T_{\text {supl.1 }}, T_{\text {sup1. } 2}$ & Air temperature inside the rack & ${ }^{\circ} \mathrm{C}$ \\
\hline$T_{\text {sup } 2.1}, T_{\sup 2.2}$ & in different positions & ${ }^{\circ} \mathrm{C}$ \\
\hline$H R_{\text {in }}$ & Air inlet humidity rate & $\%$ \\
\hline$H R_{\text {out }}$ & Air outlet humidity rate & $\%$ \\
\hline \multicolumn{3}{|c|}{ Water refrigeration } \\
\hline$T_{w . \text { in }}$ & Water inlet temperature test bench & ${ }^{\circ} \mathrm{C}$ \\
\hline$T_{w . \text { out }}$ & Water outlet temperature test bench & ${ }^{\circ} \mathrm{C}$ \\
\hline$T_{\text {sl.in }}$ & Water inlet temperature shelf 1 & ${ }^{\circ} \mathrm{C}$ \\
\hline$T_{\text {sl.out }}$ & Water outlet temperature shelf 1 & ${ }^{\circ} \mathrm{C}$ \\
\hline$T_{s 2 . i n}$ & Water inlet temperature shelf 2 & ${ }^{\circ} \mathrm{C}$ \\
\hline$T_{\text {s2.out }}$ & Water outlet temperature shelf 2 & ${ }^{\circ} \mathrm{C}$ \\
\hline$\dot{m}_{w . t}$ & Total water flow rate test bench & $1 / \mathrm{min}$ \\
\hline$\dot{m}_{w . s 1}$ & Water flow rate shelf 1 & $1 / \min$ \\
\hline$\dot{m}_{w . s 2}$ & Water flow rate shelf 2 & $1 / \mathrm{min}$ \\
\hline$P_{\text {sl.in }}$ & Inlet pressure shelf 1 & bar \\
\hline$P_{\text {sl.out }}$ & Outlet pressure shelf 2 & bar \\
\hline$P_{s 2 . i n}$ & Inlet pressure shelf 1 & bar \\
\hline$P_{\text {s2.out }}$ & Outlet pressure shelf 2 & bar \\
\hline \multicolumn{3}{|c|}{ IT equipment } \\
\hline$E_{I T}$ & Servers total power consumption & $\mathrm{W}$ \\
\hline$T_{C P U}$ & CPU temperature & ${ }^{\circ} \mathrm{C}$ \\
\hline$T_{M B}$ & Motherboard temperature & ${ }^{\circ} \mathrm{C}$ \\
\hline
\end{tabular}


Table 3

\begin{tabular}{llll}
\hline Parameter & Minimum & Maximum & Units \\
\hline Water inlet flow rate per server & 0.5 & 1.5 & $1 / \mathrm{min}$ \\
Water inlet temperature & 20 & 40 & ${ }^{\circ} \mathrm{C}$ \\
Air inlet temperature & 18 & 27 & ${ }^{\circ} \mathrm{C}$ \\
\hline
\end{tabular}


Table 4

\begin{tabular}{|c|c|c|c|c|c|c|c|}
\hline \multirow[b]{2}{*}{ Scenario } & \multirow[b]{2}{*}{ Configuration } & \multicolumn{4}{|c|}{ Liquid conditions } & \multicolumn{2}{|c|}{ Liquid cooling capacity } \\
\hline & & $\begin{array}{l}T_{\text {w.in }} \\
{\left[{ }^{\circ} \mathrm{C}\right]}\end{array}$ & $\begin{array}{c}\dot{\boldsymbol{m}}_{\boldsymbol{w}} \\
{[1 / \mathrm{min}]}\end{array}$ & $\begin{array}{l}T_{\text {w.out }} \\
{\left[{ }^{\circ} \mathrm{C}\right]}\end{array}$ & $\begin{array}{c}T_{\text {w.out }}-T_{w \text { in }} \\
{\left[{ }^{\circ} \mathrm{C}\right]}\end{array}$ & $\begin{array}{l}\dot{Q}_{I T} \\
{[\mathrm{~W}]}\end{array}$ & $\begin{array}{c}\dot{Q}_{w} \\
{[\%]}\end{array}$ \\
\hline \multirow{2}{*}{$\begin{array}{l}\text { Warmer water } \\
\text { recovered }\end{array}$} & Parallel & 40 & 1 & 49.9 & 9.9 & 1089.8 & 71.6 \\
\hline & Series & 29 & 0.5 & 50.1 & 21.1 & 1083.9 & 73.5 \\
\hline \multirow{2}{*}{$\begin{array}{l}\text { Larger water } \\
\text { temperature } \\
\text { increase }\end{array}$} & Parallel & 20 & 1 & 32.2 & 12.2 & 1059.3 & 80,7 \\
\hline & Series & 20 & 0.5 & 42.5 & 22.5 & 1066.6 & 76,3 \\
\hline \multirow{2}{*}{$\begin{array}{l}\text { Higher cooling } \\
\text { capacity ratio }\end{array}$} & Parallel & 20 & 3 & 24.2 & 4.2 & 1046.1 & 86,9 \\
\hline & Series & 20 & 1.5 & 28.3 & 8.3 & 1050.4 & 85.4 \\
\hline \multirow{2}{*}{$\begin{array}{l}\text { Minimum IT } \\
\text { consumption }\end{array}$} & Parallel & 20 & 3 & 24.2 & 4.2 & 1046.1 & 86.9 \\
\hline & Series & 20 & 1.5 & 28.3 & 8.3 & 1050.4 & 85.4 \\
\hline
\end{tabular}


Table 5

\begin{tabular}{ccccc}
\hline Component & Parameter & Definition & Value & Units \\
\hline \multirow{3}{*}{ Servers } & $C_{\text {server }}$ & Capacitance of the server & 10.5 & $\mathrm{~kJ} / \mathrm{K}$ \\
& $A_{\text {server }}$ & Heat transfer area of one server & 0.54 & $\mathrm{~m}^{2}$ \\
& $h_{\text {server }}$ & Heat transfer coefficient between server & 33.3 & $\mathrm{~W} /\left(\mathrm{m}^{2} \cdot \mathrm{K}\right)$ \\
\hline \multirow{2}{*}{ Rack } & $V_{\text {rack }}$ & and air & 0.32 & $\mathrm{~m}^{3}$ \\
& $C_{\text {rack }}$ & Capacitance of the rack & 14.7 & $\mathrm{~kJ} / \mathrm{K}$ \\
\hline
\end{tabular}


Table 6

\begin{tabular}{lccc}
\hline Definition & Nomenclature & Value & Units \\
\hline Inlet water temperature & $T_{\text {w.in }}$ & 20 & ${ }^{\circ} \mathrm{C}$ \\
Inlet air temperature & $T_{\text {airin }}$ & 22.5 & ${ }^{\circ} \mathrm{C}$ \\
Inlet air mass flow rate & $\dot{m}_{\text {air }}$ & 1740 & $\mathrm{Kg} / \mathrm{h}$ \\
Air inlet relative humidity & $H R_{\text {airin }}$ & 50 & $\%$ \\
Inlet water flow rate & $\dot{m}_{w}$ & 1 & $1 / \mathrm{min}$ \\
\hline
\end{tabular}




\section{Table 7}

\begin{tabular}{ccccc}
\hline Parameter & Scenario a) HPC & Scenario b) Data & Scenario c) Web & Scenario d) Mixed \\
\cline { 2 - 5 } & \multicolumn{4}{c}{0.5 1/min per server } \\
$\dot{Q}_{I T}[\mathrm{~kW}]$ & 17.57 & 14.74 & 11.50 & 14.29 \\
$\dot{Q}_{w}[\mathrm{~kW}]$ & 13.55 & 11.44 & 9.03 & 11.11 \\
$\dot{Q}_{w}[\%]$ & 77.12 & 77.61 & 78.52 & 77.75 \\
\hline & \multicolumn{4}{c}{1 1/min per server } \\
$\dot{Q}_{I T}[\mathrm{~kW}]$ & 17.57 & 14.74 & 11.50 & 14.29 \\
$\dot{Q}_{w}[\mathrm{~kW}]$ & 14.44 & 13.12 & 10.35 & 12.74 \\
$\dot{Q}_{w}[\%]$ & 82.19 & 89.01 & 90.00 & 89.15 \\
\hline
\end{tabular}




\section{Figures caption}

Figure 1. Detail of the water cooling system.

Figure 2. Schematic representation of the set-up, and nomenclature for the experimental measurements.

Figure 3. Evolution of the average temperatures of the CPUs and motherboards when varying the air inlet temperatures.

Figure 4. Effect on the server components temperatures and water cooling of switching off the exhaust fan, in a test with maximum IT load.

Figure 5. Scheme diagram of the TRNSYS model for the liquid cooled data centre.

Figure 6. Water outlet temperature and temperature increase (a) and water cooling power (b) depending on the water inlet temperature. Plotted for different values of total water flow rate in the parallel configuration.

Figure 7. IT power consumption and average CPU temperature, depending on the inlet temperature; for different flow rates. Parallel configuration.

Figure 8. Water outlet temperature and temperature increase (a) and water cooling power (b) depending on the water inlet temperature. Plotted for different values of total water flow rate in the series configuration.

Figure 9. Experimental data regarding inlet/outlet temperature in a server and correlation fit. Figure 10. Experimental data regarding water cooling / inlet temperature in a server and correlation fit.

Figure 11. Cooling water (a) and air (b) circuits response to an IT power change. Numerical and experimental results for a parallel system.

Figure 12. Results obtained numerically and experimentally of the water temperatures in the heat reuse experiments. Parallel case.

Figure 13. Different IT workload profiles (web, HPC, data) during a week.

Figure 14. Curves for the three types of workloads and their corresponding regression. The yaxis shows the percentage of the power referred to the maximum detected. The $\mathrm{x}$-axis shows the percentage of the IT load referred to the maximum executed.

Figure 15. Percentage of the maximum IT power consumption for different IT load distribution cases.

Figure 16. Values obtained for outlet water temperature (a) and total water cooling (b) for a system with a flow rate of $0.51 / \mathrm{min}$ per server.

Figure 17. Values obtained for outlet water temperature (a) and total water cooling (b) for a system with a flow rate of $11 /$ min per server. 
Figure 1

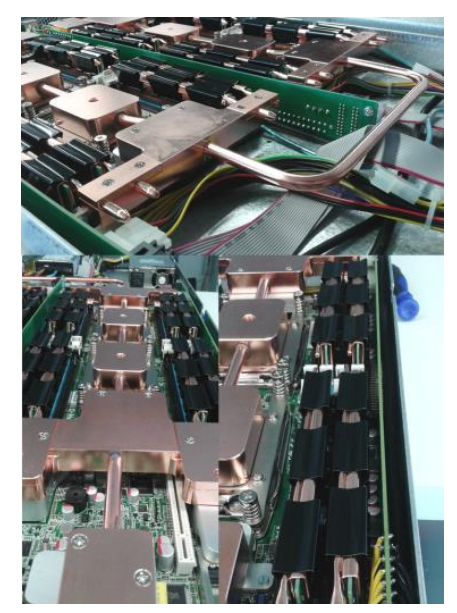


Figure 2

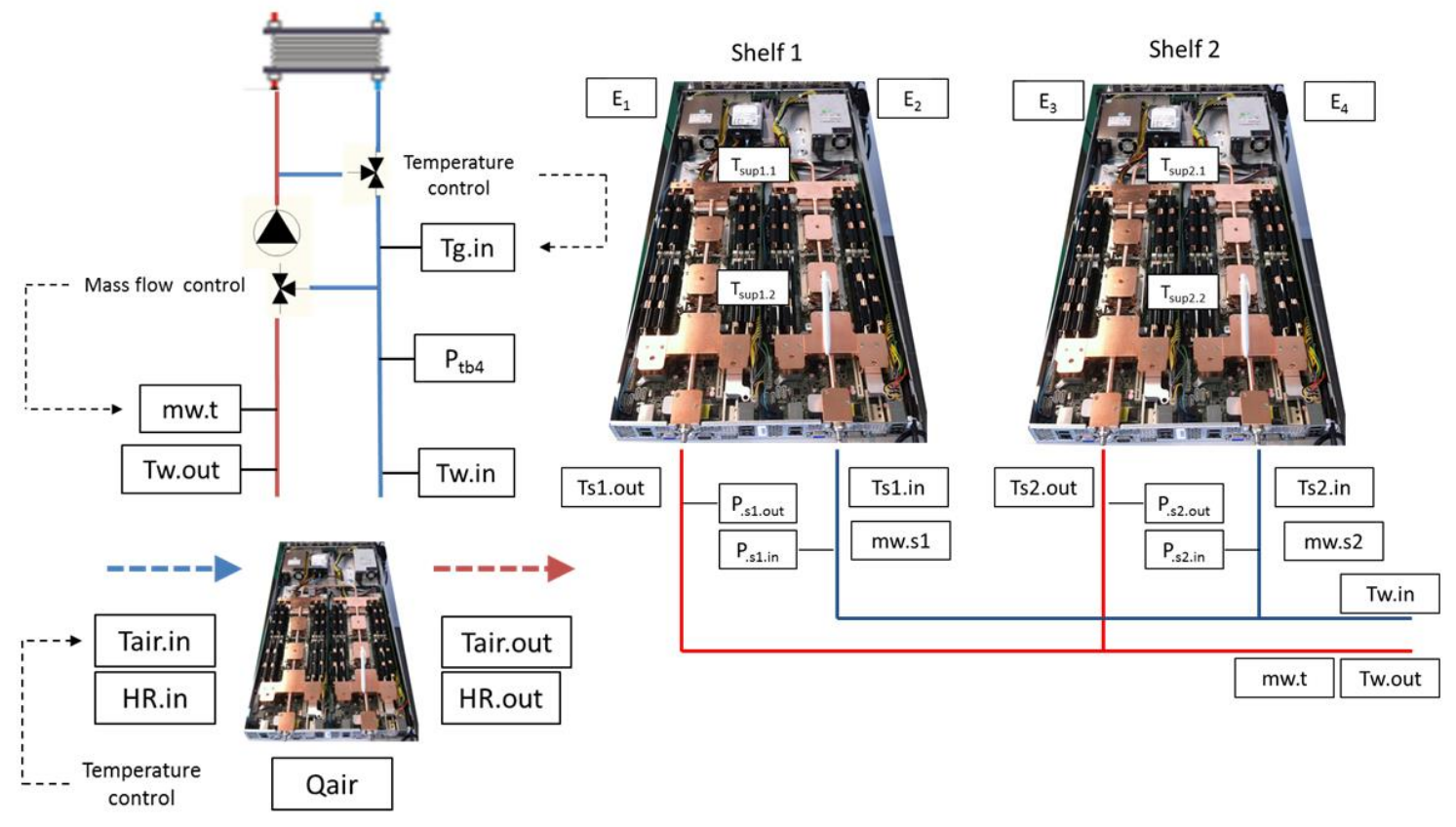


Figure 3

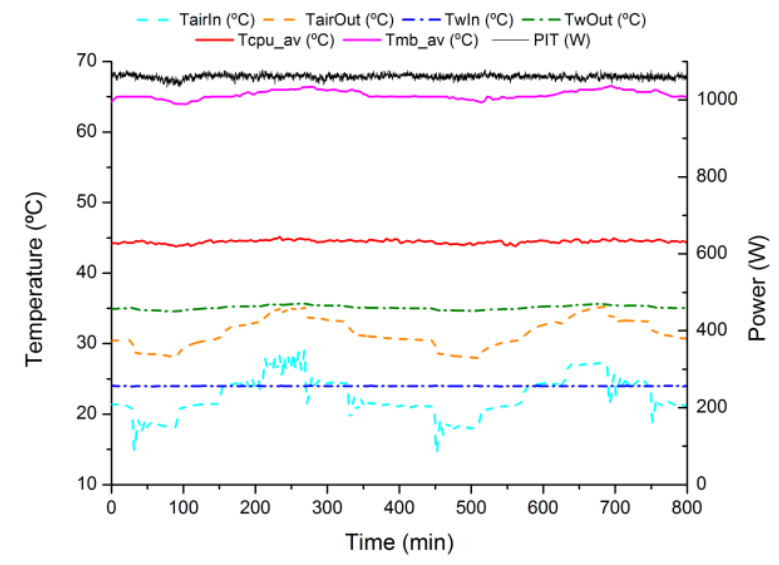


Figure 4

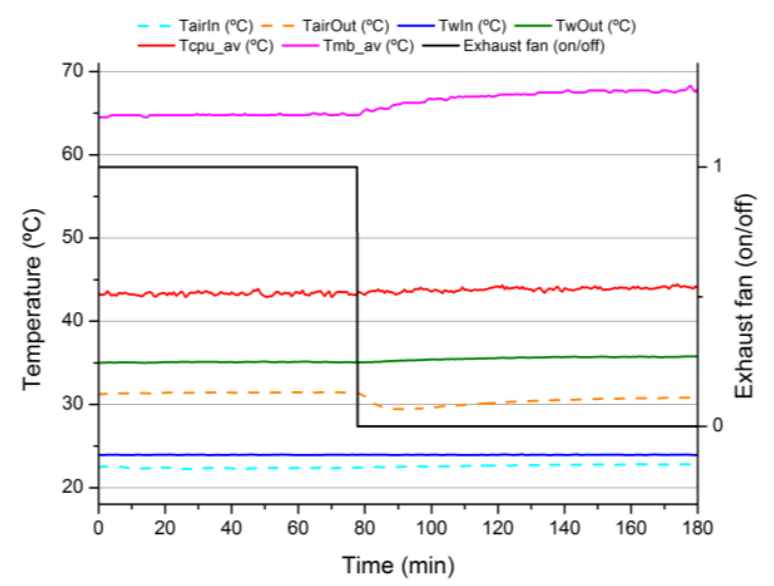


Figure 5

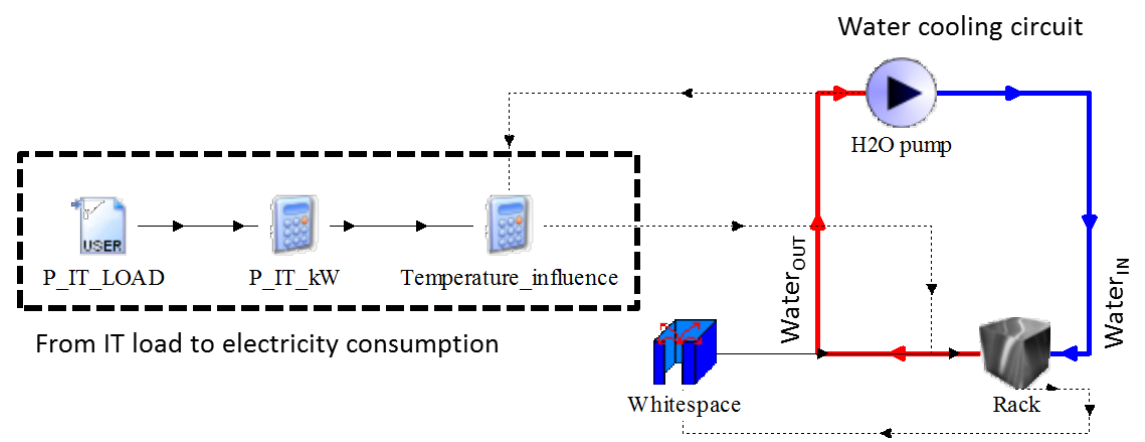


Figure 6

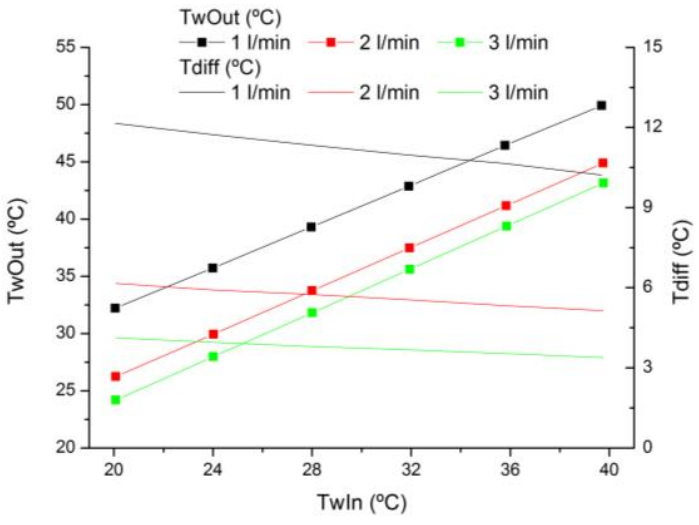

(a)

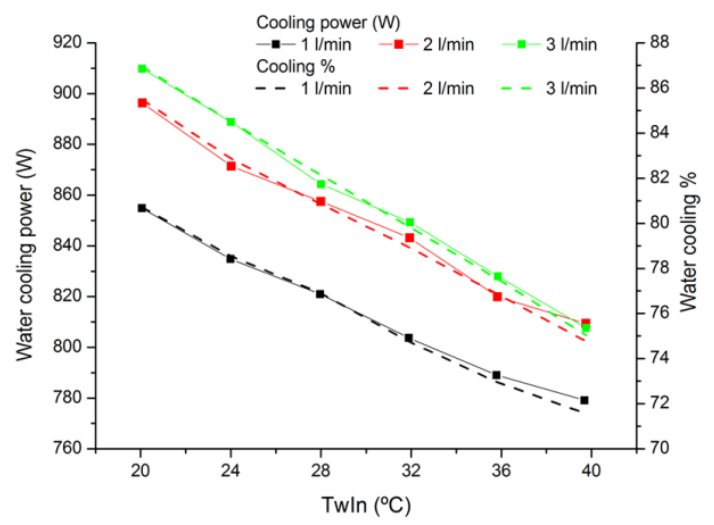

(b) 
Figure 7

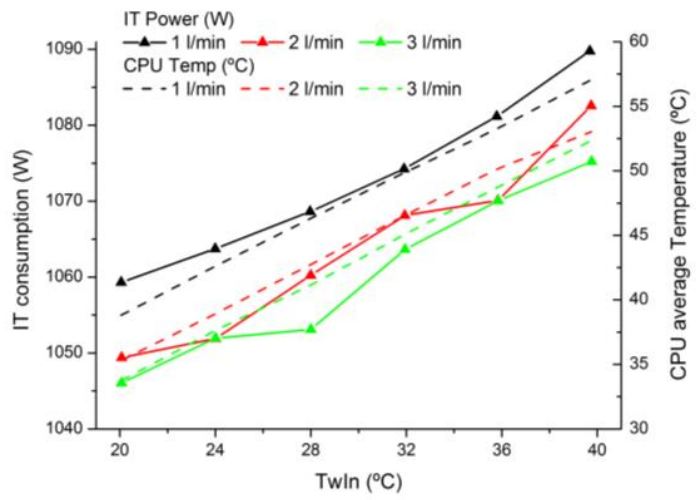


Figure 8

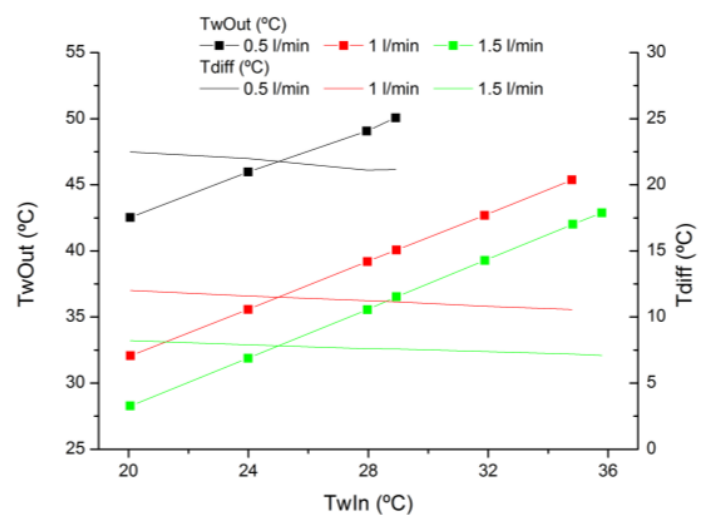

(a)

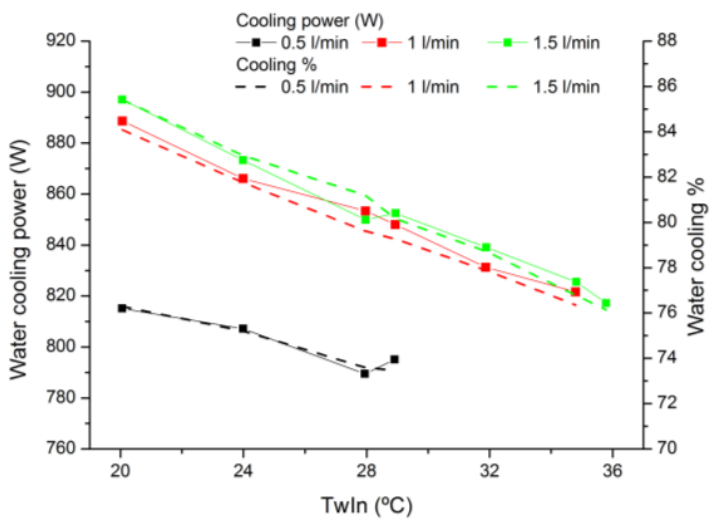

(b) 
Figure 9

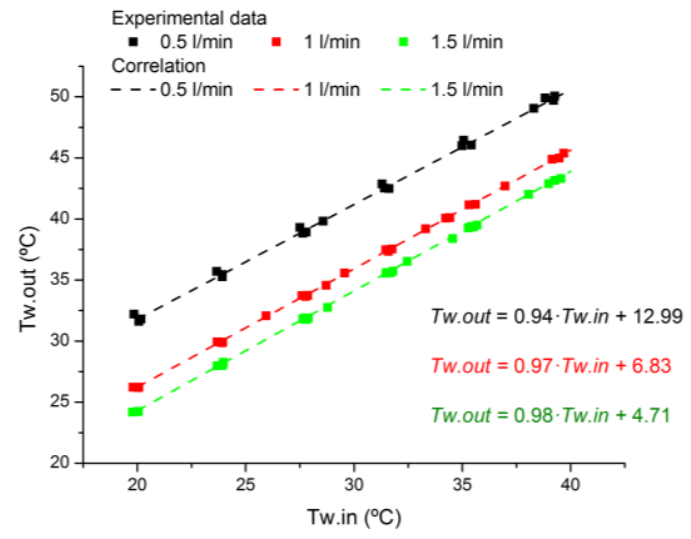


Figure 10

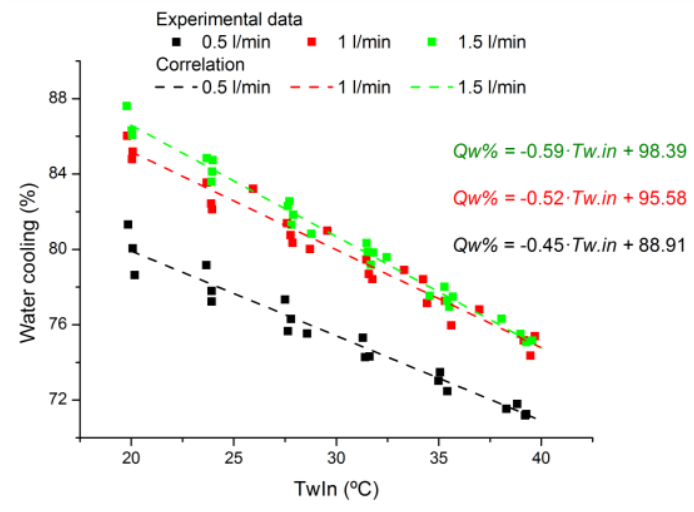


Figure 11

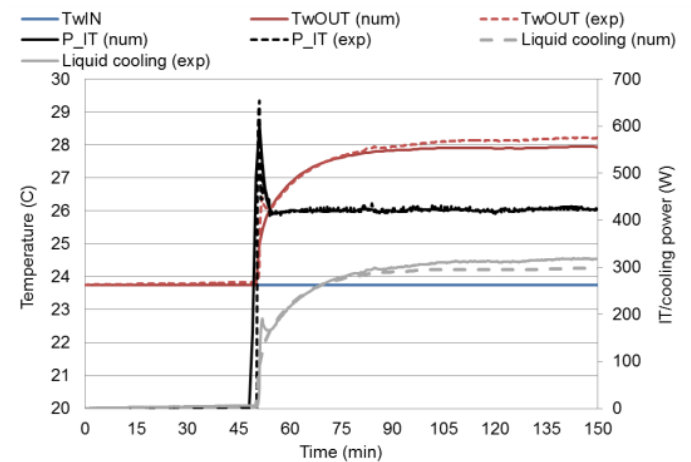

(a)

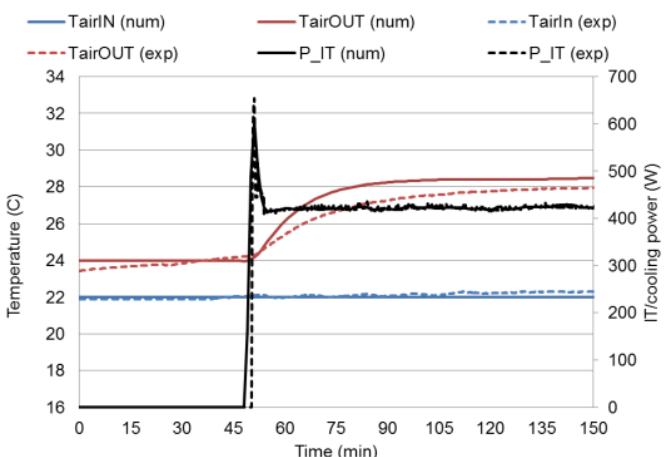

(b) 
Figure 12

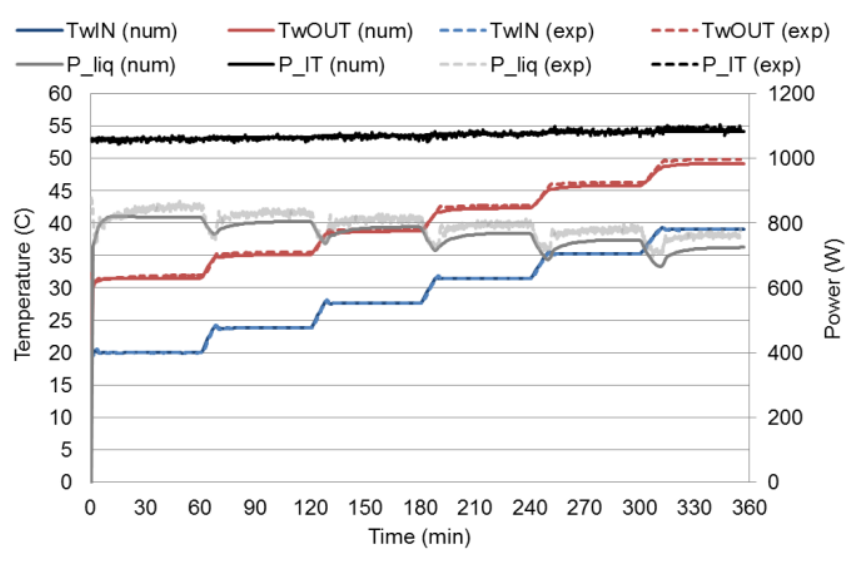


Figure 13

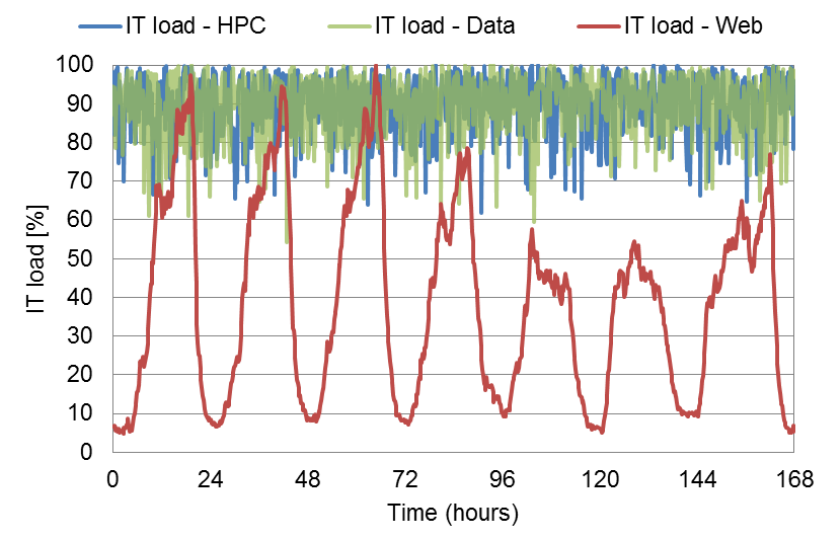


Figure 14
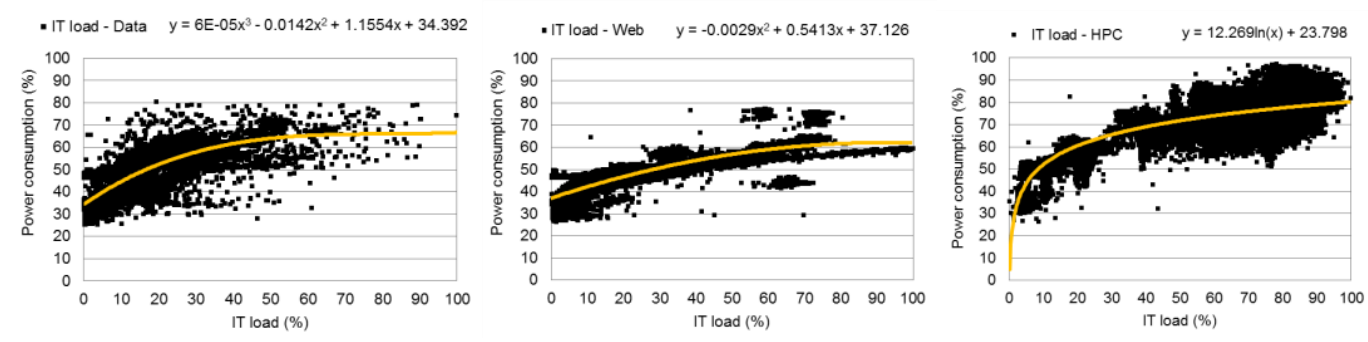
Figure 15

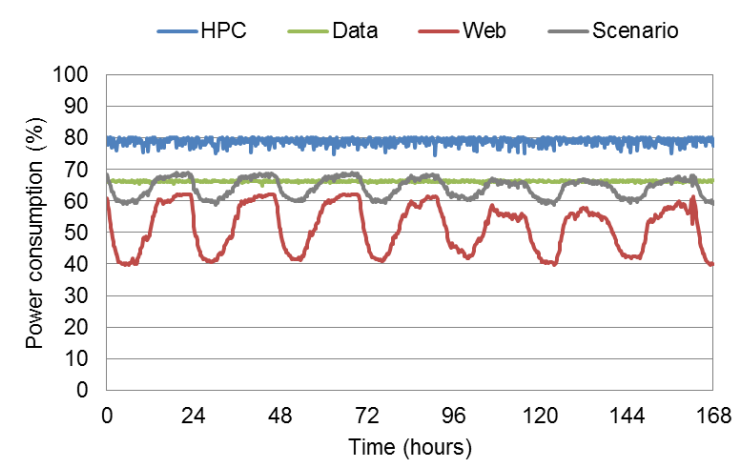


Figure 16

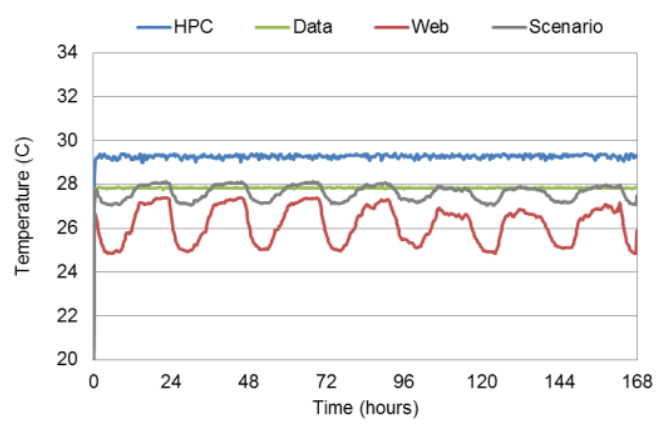

(a)

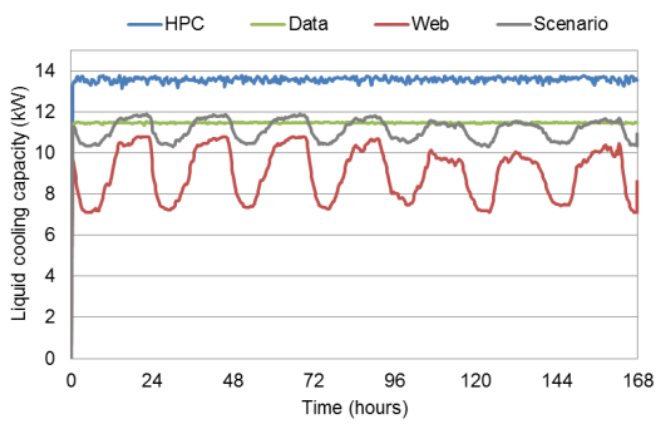

(b) 
Figure 17
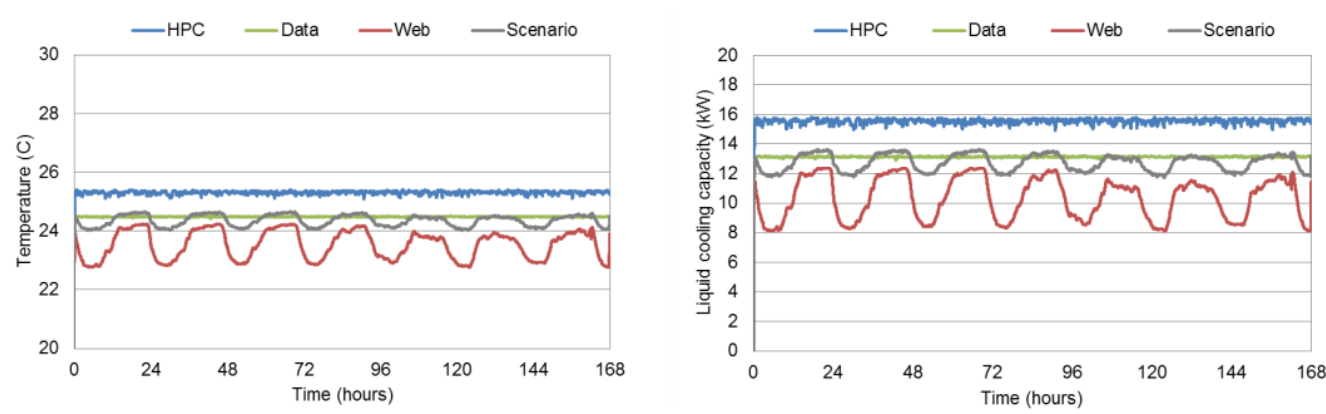

(a)

(b) 